\title{
Intestinal Urea Metabolism: Could the Bacteria Involved in Nitrogen Cycle Lead to Reutilization of Intestinal Urea Nitrogen in Uremic Rabbits?
}

\author{
Salih KAVUKÇU ${ }^{1, *}$, Mehmet TÜRKMEN ${ }^{1}$, Alper SOYLU ${ }^{1}$, Seymen BorA ${ }^{2}$, \\ Fatma YURT ${ }^{3}$ and Perihan ǗNAK ${ }^{3}$ \\ Departments of ${ }^{1}$ Pediatrics and ${ }^{2}$ General Surgery, Dokuz Eylül University \\ Medical Faculty, İzmir, Turkey \\ ${ }^{3}$ Ege University Institute of Nuclear Sciences, İzmir, Turkey \\ (Received December 26, 2001)
}

\begin{abstract}
Summary We aimed to evaluate the effect of bacteria involved in the nitrogen cycle on the reutilization of intestinal urea nitrogen in uremic rabbits. New Zealand white rabbits were made uremic via bilateral nephrectomy. Study and control rabbits were given live and heat-inactivated bacteria through their jejunostomies. After they were injected with ${ }^{99 \mathrm{~m}} \mathrm{Tc}$ biurea intravenously, serial serum and stool levels of labeled nitrogen were assessed by instant thin-layer chromatography, and the change in the labeled-nitrogen level was determined. The serum labeled-nitrogen level increased significantly in the study group $(r=0.990)$; however, this level decreased in the control group $(r=0.662)$. Furthermore, the labeled-nitrogen level in the stool samples increased throughout the study in the control rabbits, but it decreased after the 6th hour in the study group. In conclusion, the results of this study suggest that when the bacterial flora of the intestinal system is changed to include bacteria involved in the nitrogen cycle in uremic rabbits, the intraintestinal and systemic nitrogen metabolisms could both be altered in favor of positive nitrogen balance.
\end{abstract}

Key Words nitrogen cycle, nitrifying bacteria, nutrition, urea, uremia.

In mammals, urea nitrogen is converted to ammonia by enteric flora bacteria in enterohepatic circulation and excreted in the feces as illustrated in Fig. 1. In uremia, the intestinal urea level increases in parallel with the serum level (1). Enteral antibiotics lead to an approximation of intraluminal urea concentrations in the intestines to the plasma levels and to a decrease in fecal ammonia levels in healthy subjects (2). This is also true for uremic patients who have higher fecal ammonia levels than the healthy controls (3). The elimination of intestinal flora bacteria, which convert urea nitrogen to fecal nitrogen, has been proposed to increase the bioavailability of urea nitrogen. The oral administration of neomycin and kanamycin to uremic patients resulted in a decrease in endogenous fecal nitrogen and to improved nitrogen balance (4). Isotopic studies performed in the humans and animals have shown that the daily amount of urea metabolized by the enteric flora bacteria is about $7 \mathrm{~g}$, which is more than $20 \%$ of daily urea production and $40 \%$ of the urea pool (5). Many studies are being conducted to improve the impaired protein metabolism in uremic children, such as the use of essential amino acids and the $\alpha$-ketoacids of these amino acids (6). However, these efforts did not significantly improve protein metabolism, nutrition, and growth in these children. The reutilization of intestinal urea nitrogen, which is normally excreted in the feces, might be

* To whom correspondence should be addressed: Mithatpaşa Cad. No: 665/4, 35280 Küçükyali, Izmir, Turkey.

E-mail: s.kavukcu@deu.edu.tr an alternative solution for the nutrition and growth problems in uremic or nonuremic children.

Some plants can use free nitrogen in the air. The most significant group of plants that have this property is the leguminosae. The Rhizobium species-a Gram negative, aerobic, and motile rod living in the roots of leguminosae-fix the free nitrogen of the air by oxidation (7). The first product of nitrogen fixation is ammonia $\left(\mathrm{NH}_{3}\right)$. The oxidation of $\mathrm{NH}_{3}$ to nitrate (nitrification) is performed by obligatory aerobic chemoautotrophic bacteria in two steps. First, $\mathrm{NH}_{3}$ is converted to nitrite $\left(\mathrm{NO}_{2}\right)$; then $\mathrm{NO}_{2}$ is converted to nitrate $\left(\mathrm{NO}_{3}\right)$. The prototype of bacteria synthesizing $\mathrm{NO}_{2}$ from $\mathrm{NH}_{3}$ is Nitrosomonas, and that of converting $\mathrm{NO}_{2}$ to $\mathrm{NO}_{3}$ is Nitrobacter. These nitrifying bacteria are small Gram-negative rods and are found extensively both in soil and water (8). Nitrogen, which is usually taken in the form of nitrates $\left(\mathrm{NO}_{3}\right)$ in the soil, is reduced by some microorganisms and higher plants to be incorporated into the structure of amino acids and proteins. When the dead plants and animals putrefy, nitrogen reenters the soil in the form of ammonia $\left(\mathrm{NH}_{3}\right)$. The nitrogen of ammonia is oxidased to form $\mathrm{NO}_{3}$ by the nitrifying bacteria (7).

The maximal metabolism of dietary protein could be an important solution for the undernutrition and growth failure in uremic as well as in nonuremic children. The aim of this study was to evaluate the effect of the bacteria involved in the nitrogen cycle on the reutilization of intestinal urea nitrogen in uremic rabbits. Biurea was used as the nitrogen source. 


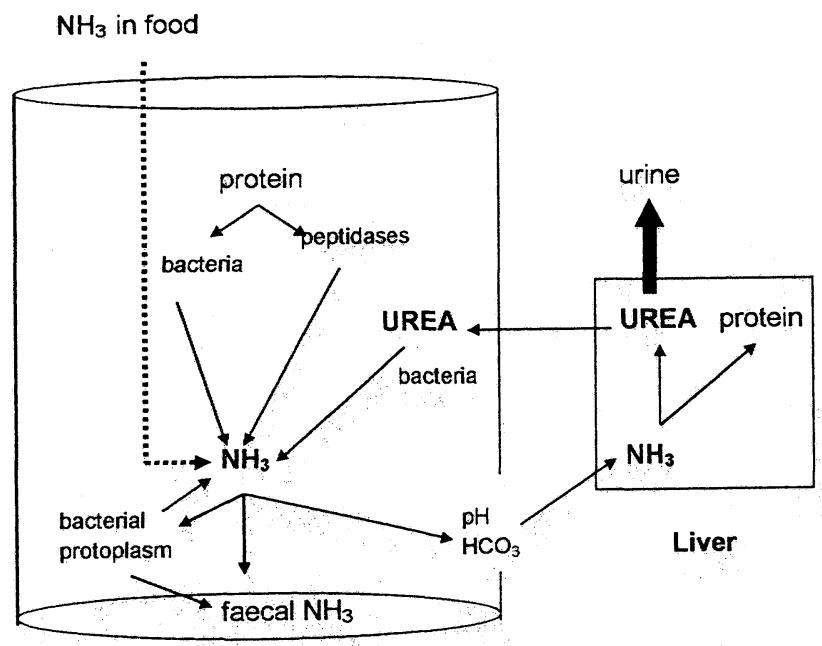

Intestinal lumen

Fig. 1. Enterohepatic cycle of urea nitrogen.

\section{MATERIALS AND METHODS}

Experimental animals. Twenty New Zealand white rabbits (Orytolagus cuniculus) were enrolled in the study. All the rabbits were fed with standard pellets for $3 \mathrm{wk}$ in laboratory conditions. They were kept at room temperature and at 12-h light-dark cycles with free access to water. Their weights were determined at the onset of the study.

Uremia model. All the animals were anesthesized by intraperitoneal ketamin $(80 \mathrm{mg} / \mathrm{kg})$ and inhalational ether. After that, a midline incision in the abdomen was performed to reach the peritoneal space. Both renal pedicles (including the renal vein, artery, and ureter) were then ligated with $5 / 0$ silk, and blanching of the kidneys were noted.

Jejunostomy operation. At the same session, an $8 \mathrm{Fr}$ feeding tube was inserted into the proximal jejunum and exteriorized through skin on the back of each rabbit (Stamm-type tube jejunustomy) (9).

Preparations of the bacterial solutions

Nitrosomonas: One milliliter of Nitrosomonas solution was inoculated into the tubes containing $4 \mathrm{~mL}$ mixture of macroelements $\left(\mathrm{K}_{2} \mathrm{HPO}_{4}, \mathrm{MgSO}_{4}, \mathrm{CaCl}_{2}\right)+$ microelements $\left(\mathrm{H}_{3} \mathrm{BO}_{3}, \mathrm{Na}_{2} \mathrm{MoO}_{4}, \mathrm{CoCl}_{2}, \mathrm{MnCl}_{2}, \mathrm{CuSO}_{4}, \mathrm{ZnSO}_{4}\right.$, $\left.\mathrm{NiSO}_{4}\right)+$ iron chelate $+\left(\mathrm{NH}_{4}\right)_{2} \mathrm{SO}_{4}$ + bromothymol blue + sterile water. After $28 \mathrm{~d}$ of incubation at $28^{\circ} \mathrm{C}$, when the color of the solution turned to yellow, the bacteria count was calculated by the method of MPN (most probable number) $(10,11)$. Each milliliter of the solution included about $10^{3}$ bacteria.

Nitrobacter: One milliliter of Nitrobacter solution was inoculated into the tubes containing $4 \mathrm{~mL}$ mixture of macroelements + microelements + iron chelate $+\mathrm{KNO}_{2}+$ sterile water. After $28 \mathrm{~d}$ of incubation at $28^{\circ} \mathrm{C}$, in the presence of sulfanylamide- $N$-(1-naphtyl)-ethylendiamine hydrochloride indicator reacting with preformed nitrate, the bacteria count was calculated by the method of MPN $(10,11)$. Each milliliter of the solution included about $10^{3}$ bacteria.

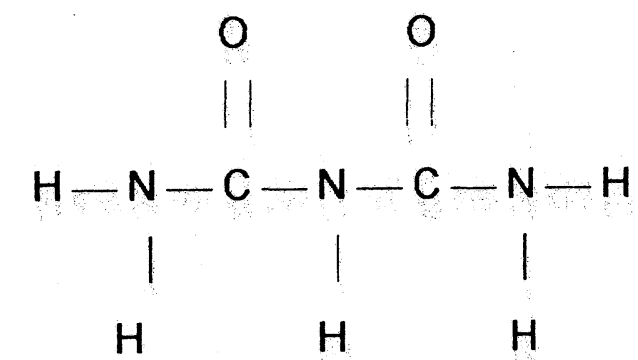

Fig. 2. Structure of biurea. ${ }^{99 \mathrm{~m}} \mathrm{Tc}$ binds to any of the nitrogen atoms in the molecule.

Rhizobium: Clover roots were used as the source of Rhizobium, since this bacterium could not be grown at in vitro conditions to form specific solution. Thus $500 \mathrm{~g}$ of ground clover roots was suspended in $1,000 \mathrm{~mL}$ of sterile water, and this solution was used as the source of Rhizobium. The presence of Rhizobium bacteria in this suspension was confirmed by an inoculation of $1 \mathrm{~mL}$ of suspension into the petri dishes containing Yeast Extract Mannitol Agar solid medium and incubation for $5 \mathrm{~d}$ at $28^{\circ} \mathrm{C}$. After the incubation period, Rhizobium colonies grown in the solid medium were counted (12).

Labeling of biurea with ${ }^{99 m}$ Technetium $\left({ }^{99 m} \mathrm{Tc}\right)$. Urea and $\mathrm{SnCl}_{2} \cdot 2 \mathrm{H}_{2} \mathrm{O}$ were purchased from Merck. $\mathrm{Na}^{99 \mathrm{~m}} \mathrm{TcO}_{4}$ was obtained from Department of Nuclear Medicine of Ege University.

Biurea (Fig. 2) was prepared as follows: Dry urea of $10 \mathrm{mg}$ was heated for $2 \mathrm{~h}$ at $200^{\circ} \mathrm{C}$.

${ }^{99 m}$ Tc-biurea: Freshly prepared $\mathrm{SnCl}_{2} \cdot 2 \mathrm{H}_{2} \mathrm{O}$ solution $(1 \mathrm{mg} / 1 \mathrm{~mL} 0.1 \mathrm{~N} \mathrm{HCl})$ was added to freshly prepared biuret $(2.5 \mathrm{mg} / \mathrm{mL})$ solution in a tube. Then approximately $0.3-0.5 \mathrm{mCi}(11.1-18.5 \mathrm{MBq}) \mathrm{Na}^{99} \mathrm{TcO}_{4}$ was added and allowed to settle for 20-25 min at room temperature. Labeling yield was checked by radio-TLC, radio-HPLC, and radio-paper electrophoresis. Labeling yield and specific activity exceeded $90 \%$ and $3.10^{10}$ $\mathrm{Bq} / \mathrm{mmol}$, respectively.

Radio-TLC conditions: ${ }^{99 \mathrm{~m}} \mathrm{Tc}$-biurea was analyzed by the use of TLC supply using cellulose-coated plastic sheets (Merck 5565). These sheets were cut into $1 \times 10 \mathrm{~cm}$ strips. A point was marked at $1 \mathrm{~cm}$ from one end as a marker for the origin. The samples of $5 \mu \mathrm{L}$ were applied here, and without drying the spots were developed immediately. Two solvent systems were used: $20 \%$ dextrose solution and $20 \%$ citrate acid as eluant. The solvents were allowed to reach about $8 \mathrm{~cm}$ from the origin. The strips were dried and cut into $0.5 \mathrm{~cm}$ pieces. The radioactivity of each piece was determined in a gamma well-type $\mathrm{NaI}(\mathrm{Tl})$ scintillation detector of a multichannel analyzer. The $R f$ values and labeling yield of ${ }^{99} \mathrm{~m}$ Tc-biurea were calculated from the strip developed in both solvent systems.

Electrophoresis was done with a Gelman electrophoresis chamber supply using cellulose acetate strips $(25 \times 1 \mathrm{~cm})$. After the strips were moisturized by buffer solution $(0.8 \mathrm{~mL}$ glacial acetic acid and $10 \mathrm{~mL}$ pyridine made up to $250 \mathrm{~mL}$ with distilled water, $\mathrm{pH}$ 6.1), a sample was applied on a marked strip. This strip 


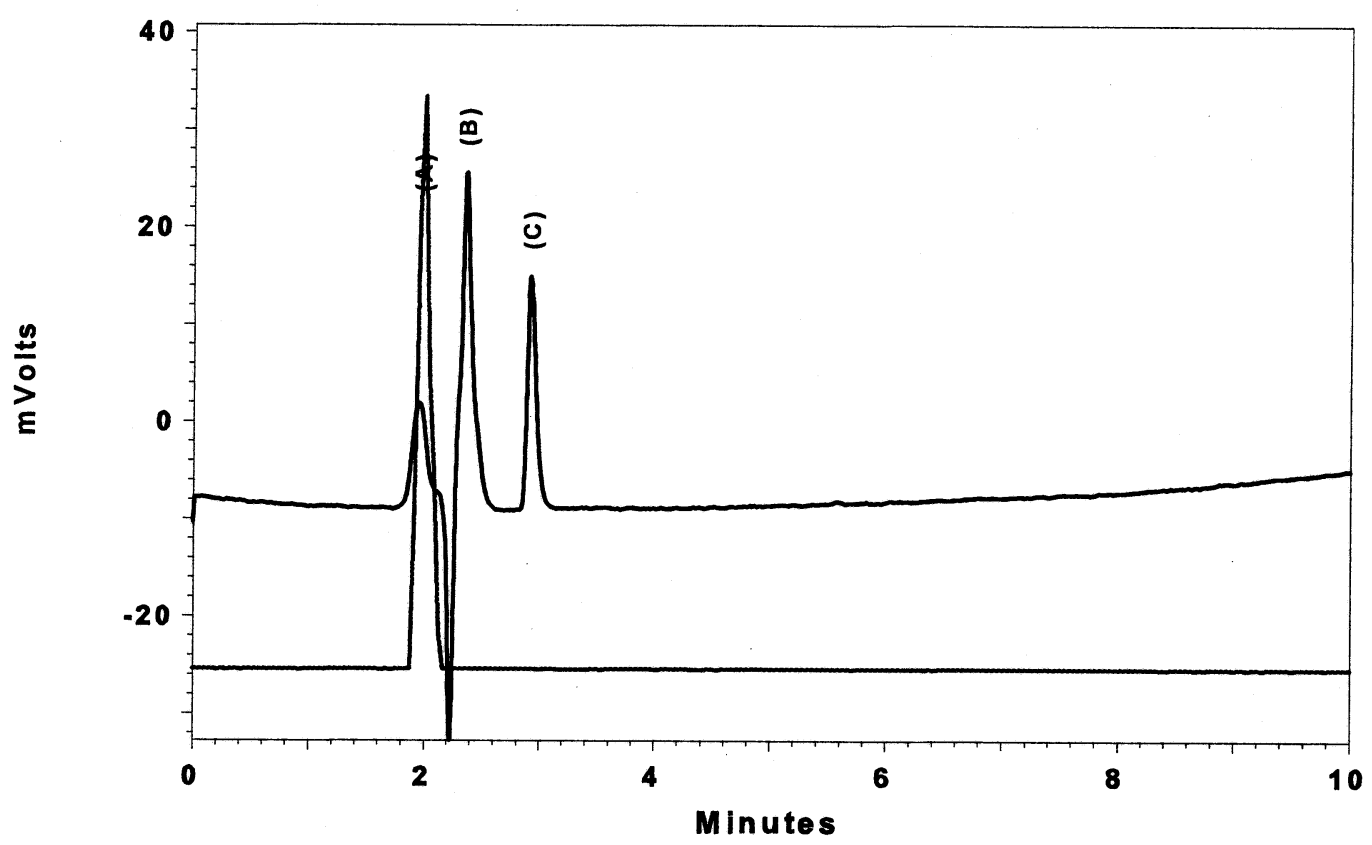

Fig. 3. HPLC (upper line) and radio-HPLC (lower line) chromatograms. The first peak and the negative peak in HPLC come from the eluent buffer at the UV detector. The retention times of urea (C peak), biuret (B peak), and ${ }^{99 \mathrm{~m}} \mathrm{Tc}-$ biuret (A peak) are 2.92, 2.36 , and $1.97 \mathrm{~min}$, respectively. ${ }^{99 \mathrm{~m}} \mathrm{Tc}$-biuret has been detected by the $\mathrm{Cd}(\mathrm{Te})$ detector; others have been detected by the UV detector at $195 \mathrm{~nm}$.

was settled in the electrophoresis chamber. Applied voltage was $250 \mathrm{~V}$, and standing time was $2 \mathrm{~h}$. The developed strip was then dried and cut into $1 \mathrm{~cm}$ pieces, and each piece was counted by a $\mathrm{NaI}(\mathrm{Tl})$ scintillation detector.

HPLC (Shimadzu LC-10 TvP) with a UV detector (Shimadzu SPD-10AvP) and equipped with a $\mathrm{Cd}(\mathrm{Te}) \mathrm{de}-$ tector (RAD 501) was used to check the ${ }^{99 \mathrm{~m}} \mathrm{Tc}$-biurea structure. HPLC conditions: the UV detector was settled to $195 \mathrm{~nm}$. Column: 250/4.6 Nucleosil 100-5 C-18, Eluent: $0.02 \mathrm{M} \mathrm{Na}_{2} \mathrm{HPO}_{4}$ buffer and $0.005 \mathrm{M}$ dodecylbenzene sulfonate were mixed and adjusted to $\mathrm{pH} 5.5$ with orthophosphoric acid. The flow rate of eluent was $1.0 \mathrm{~mL} / \mathrm{min}$. The obtained chromatograms for biuret, urea, and ${ }^{99 \mathrm{~m}} \mathrm{Tc}$-biurea at UV and radioactivity detectors were shown in Fig. 3.

Administration of bacterial solutions. After bilateral ligation of renal pedicles and jejunostomy, 10 rabbits (study group) were given $10 \mathrm{~mL}$ of each bacterial solution four times at 3 -h periods $(0,3,6$, and 9 postoperative hours) through jejunostomies. The remaning 10 rabbits (control group) were given the same amount of heat-inactivated (at $100^{\circ} \mathrm{C}$ for $30 \mathrm{~min}$ ) bacterial solutions by the same route.

Administration of ${ }^{99 m}$ Tc-biurea to the rabbits and obtaining blood and stool samples. At the postoperative 12th hour, an intravenous access through an ear vein was performed for each rabbit. First, $1 \mathrm{~mL}$ of blood was obtained for baseline analyses; then $5 \mathrm{mCi} / \mathrm{kg}$ of ${ }^{99 \mathrm{~m}} \mathrm{Tc}-\mathrm{bi}-$ urea solution was injected into each rabbit. After that, at the 5 th minute $(0 \mathrm{~h})$ and every $2 \mathrm{~h}$ thereafter, $1 \mathrm{~mL}$ of blood samples was obtained for $8 \mathrm{~h}$ (2nd, 4th, 6th, and 8th hours). Further, each stool sample of each rabbit was obtained, and the time of defecation was noted dur- ing this 8-h period.

Analysis of ${ }^{99 m} \mathrm{Tc}$-biurea levels in the blood and stool samples. Each timely obtained blood and stool sample was analyzed for change in the level of ${ }^{99 \mathrm{~m}} \mathrm{Tc}$-labeled nitrogen by ITLC. The change in the level of the labeled-nitrogen with respect to time was calculated for each rabbit, and the mean values for the study and control groups were determined. A calculation of the radioactivity of samples was performed by a well-hole-type scintillation detector with multichanneled $\mathrm{NaI}(\mathrm{Tl})$ analyzer, through setting for a $141 \mathrm{keV} \gamma$-photon peak of ${ }^{99 \mathrm{~m}}$ Tc. The results obtained by radio-TLC were controlled by radio-HPLC and radioelectrophoresis.

Further, blood urea nitrogen (BUN) level was determined in each blood sample by the routine spectrophotometric method (DACOS XL autoanalyser).

\section{Bacterial culture of the stool samples}

Nitrosomonas and Nitrobacter: After the stool samples were weighed and homogenized in sterile water, they were inoculated into the culture mediums defined previously $(10,11)$. At the end of an incubation period, bacteria count was determined by the MPN method and expressed as "number of bacteria per one gram of stool."

Rhizobium: The presence of Rhizobium in stool homogenates was confirmed by an inoculation of $1 \mathrm{~mL}$ of suspension into the petri dishes containing yeast extract mannitol agar solid medium and incubation for $5 \mathrm{~d}$ at $28^{\circ} \mathrm{C}$. After the incubation period, Rhizobium colonies grown in the solid medium were counted (12).

Statistical analyses. A statistical evaluation of the results was performed via an SPSS computer program using Friedman, Wilcoxon signed rank and MannWhitney $U$ tests. 


\section{RESULTS}

The mean weights of the study and control rabbits were $2,003 \pm 137$ and $1,985 \pm 168 \mathrm{~g}$, respectively $(p>0.05)$. Because two of the study and one of the control rabbits died during the early postoperative period, the study was completed with 17 rabbits.

BUN levels at the onset and throughout the study did not differ between the groups. On the other hand, the increase of BUN with respect to time was significant in both groups (Table $1, p<0.005$ ). Labeled-biurea solutions given at the onset of the study did not significantly affect the BUN levels of the rabbits. This is verified by similar BUN levels measured before and $5 \mathrm{~min}$ after the

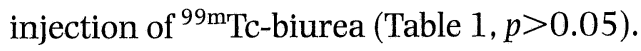

Table 1. The mean blood urea nitrogen levels of the study and control rabbits (mean $\pm \mathrm{SD}$ ).

\begin{tabular}{|c|c|c|c|}
\hline \multirow[b]{2}{*}{ Time } & \multicolumn{2}{|c|}{ Blood urea nitrogen (mg/dL) } & \multirow[b]{2}{*}{$p$} \\
\hline & $\begin{array}{l}\text { Study group } \\
\quad(n=8)\end{array}$ & $\begin{array}{l}\text { Control group } \\
\quad(n=9)\end{array}$ & \\
\hline Onset $^{3}$ & $83.33 \pm 22.12$ & $85.14 \pm 34.04$ & 0.952 \\
\hline O hours ${ }^{3}$ & $83.38 \pm 22.15$ & $89.44 \pm 19.20$ & 0.736 \\
\hline 2nd hour & $91.63 \pm 15.68$ & $101.11 \pm 26.07$ & 0.630 \\
\hline 4th hour & $101.71 \pm 15.90$ & $111.67 \pm 24.12$ & 0.525 \\
\hline 6th hour & $107.63 \pm 18.57$ & $113.44 \pm 28.72$ & 0.847 \\
\hline 8th hour & $115.90 \pm 20.25$ & $120.56 \pm 31.33$ & 1.000 \\
\hline$p$ & 0.0002 & 0.0000 & \\
\hline
\end{tabular}

${ }^{1}$ Blood urea nitrogen levels increased significantly with time $(p=0.0002)$.

${ }^{2}$ Blood urea nitrogen levels increased significantly with time $(p=0.0000)$.

${ }^{3}$ The values measured before (onset) and after $5 \mathrm{~min}(0$ hours) of injection of the radiolabeled-nitrogen. Blood urea nitrogen levels measured in these periods were the same in both groups $(p>0.05)$.

Table 2. The percentage of the blood labeled-nitrogen activity in comparison to the radioactivity of the original solution in the study and control rabbits (mean \pm SD).

\begin{tabular}{|c|c|c|c|}
\hline \multirow{2}{*}{ Time } & \multicolumn{2}{|c|}{$\begin{array}{l}\text { Blood labeled-nitrogen activity } \\
\text { (\% of dose) }\end{array}$} & \multirow{2}{*}{$p$} \\
\hline & $\begin{array}{l}\text { Study group } \\
\quad(n=8)\end{array}$ & $\begin{array}{l}\text { Control group } \\
\quad(n=9)\end{array}$ & \\
\hline 0 hours $^{3}$ & $45.63 \pm 14.04$ & $37.22 \pm 14.25$ & 0.247 \\
\hline 2nd hour & $35.38 \pm 7.84$ & $36.00 \pm 5.81$ & 0.961 \\
\hline 4th hour & $35.88 \pm 8.41$ & $25.33 \pm 6.80$ & 0.015 \\
\hline 6th hour & $40.00 \pm 5.73$ & $33.00 \pm 6.95$ & 0.050 \\
\hline 8th hour & $41.63 \pm 3.62$ & $28.67 \pm 7.05$ & 0.001 \\
\hline
\end{tabular}

\footnotetext{
${ }^{1}$ The change in the radioactivity because of labeled-nitrogen in time was not significant $(p=0.080)$.

${ }^{2}$ The change in the radioactivity because of labeled-nitrogen in time was not significant $(p=0.097)$.

${ }^{3}$ The values measured after 5 min of injection of the radiolabeled-nitrogen.
}

The level of radioactivity because of labeled-nitrogen in the blood samples of study and control groups at the 5 th minute of injection was 45.63 and $37.22 \%$, respectively, of the radioactivity of the original biurea solution (Table 2). Radioactivity decreased at the 2nd hour, remained stable at the 4 th hour, and tended to increase at the 6 th and 8 th hours in the study group (Table 2). The changes in the level of labeled-nitrogen with time, however, was not significant in this group $(p=0.080)$. The levels in the control group decreased progressively at the 2 nd and 4 th hours, tended to increase at the 6 th hour (though it was lower than at the 2 nd hour), and again decreased at the 8 th hour. The changes in the level of labeled nitrogen with time was also not significant in the control group $(p=0.097)$. The results obtained by radio-TLC were supported by radio-HPLC and radioelectrophoresis methods.

When the changes in the level of labeled-nitrogen in the study and control groups were compared, the levels at the onset and 2 nd hour were not different. On the other hand, the study rabbits were determined to have significantly higher levels at the 4 th, 6th, and 8th hours $(p=0.015, p=0.050$, and $p=0.001$, respectively) (Table 2).

When the relation of the BUN level to time was analyzed, the study and the control groups both showed a significant positive correlation $(r=0.394, p<0.05$, and $r=0.571, p<0.05$, respectively).

When the relation of blood labeled-nitrogen level to time was analyzed, there was a rapid decline during the first $30 \mathrm{~min}$ after the initial peak level in the study group. After that, the labeled-nitrogen level increased in time $(r=0.990)$. The control group, however, showed a progressive decline $(r=0.662)$ after an initial peak. The stool labeled-nitrogen level in the study group reached a peak at the 6 th hour, then declined again.

The stool samples of both the study and control rabbits were cultured for all three types of bacteria. Rhizobium could not be grown in either group. The numbers of Nitrosomonas and Nitrobacter grown in $1 \mathrm{~g}$ of stool in the study group were 98.75 106.09 and $2.00 \pm 2.30$, respectively. The corresponding values for

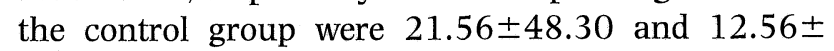
12.13, respectively. Although the study group had a significantly higher number of Nitrosomonas colonies $(p=0.019)$, the number of Nitrobacter did not differ between the groups $(p=0.190)$.

\section{DISCUSSION}

A probiotic is a viable microbial dietary supplement that beneficially affects the host through its effects in the intestinal tract. Probiotics are widely used to prepare fermented dairy. In the future they may also be found in fermented vegetables and meats. Several health-related effects associated with the intake of probiotics, including an alleviation of lactose intolerance and immune enhancement, have been reported in human studies (13). Probiotics are also used in veterinary medicine to decrease the elimination of food with feces, increase the availability of undigested food, and 
eliminate harmful microorganisms from the intestinal flora. Cattle administered probiotics are reported to gain normal weight with lower energy intake (14). In this study, the probiotic effect of the bacteria involved in the nitrogen cycle, when inoculated into the intestinal flora of uremic rabbits, was evaluated in promoting the use of intestinal urea nitrogen in protein synthesis.

Biurea was chosen as the nitrogen source in this experiment. It has been demonstrated previously that biurea stabilized by isobutylidene (isobutylidene diurea) is equal to or even better than urea as a nitrogen supply for rumen microbes $(15,16)$.

BUN levels increased throughout the study period in both the study and control groups and did not differ between them. The blood labeled-nitrogen level, however, decreased progressively in the control group, but increased after a period of fall in the study group. This indicates that labeled-nitrogen entering the intestinal lumen of these rabbits is reutilized by the effect of liveinoculated bacteria. A decline of labeled-nitrogen after $6 \mathrm{~h}$ in the stool samples of this group of rabbits also supports the previous finding.

The ITLC method used in this study enabled us to discriminate ${ }^{99 \mathrm{~m}} \mathrm{Tc}$ bound to nitrogen from free ${ }^{99 \mathrm{~m}} \mathrm{Tc}$ detached from nitrogen (17). Thus only the ${ }^{99 \mathrm{~m}} \mathrm{Tc}$ bound to nitrogen was used in the measurements, and free ${ }^{99 m} \mathrm{Tc}$ did not effect the results. However, increased labeled-nitrogen levels detected after the fourth hour of study in the study group might reflect the presence of the ${ }^{99 \mathrm{~m}} \mathrm{Tc}$-biurea or other molecule(s) binding labelednitrogen, such as amino acids and peptides. The results obtained by ITLC were supported by radio-HPLC and radioelectrophoresis. However, these methods are unable to discriminate the nature of molecule(s) binding labeled-nitrogen. Thus other techniques are needed to evaluate the nature of molecule(s) binding labeled-nitrogen in this group of rabbits.

Although the study and control groups differed significantly with respect to the blood labeled-nitrogen level, we could not compare them with respect to change in the level of ${ }^{99 \mathrm{~m}} \mathrm{Tc}$-labeled-nitrogen in the stool. This was because of the discordance in time in obtaining the stool samples from the animals.

We used enterostomy to inoculate the bacteria into the intestinal lumen (9). We did this because bacteria administered orally might be inactivated by oral or gastric secretions. In the future it may be possible to prepare oral formulations of these bacteria.

The growth of Rhizobium, Nitrosomonas, and Nitrobacter in stool cultures is the gold standard for demonstrating the colonization of these bacteria in the intestinal lumen of the rabbits. Although Nitrosomonas and Nitrobacter were cultured in the stool samples of both groups, Rhizobium could not be grown in either. On the other hand, the role of Rhizobium in the nitrogen cycle is to fix free nitrogen in the air (7). Thus Nitrosomonas and Nitrobacter are probably more important as far as the use of nitrogen incorporated into the structure of ammonia in the intestinal lumen is considered. In other words, we believe that the failure of colonization of
Rhizobium in the intestinal lumen of the rabbits did not affect the kinetics of this study. Although both Nitrosomonas and Nitrobacter were supposed to be grown in higher numbers in the study rabbits, only the number of Nitrosomonas was higher significantly in this group. This finding suggests that either Nitrobacter is found naturally in the intestines of rabbits or that heat-inactivation was not completely successful for Nitrobacter. In either case, presence of Nitrosomonas in the same medium seems to complete the cycle.

The compatibility of these bacteria with the normal intestinal flora of the rabbits was not known before the study. To promote the colonization of these bacteria in the intestinal lumen, enteral antibiotic administration could be considered (6). However, because these bacteria require nitrogen in the form of ammonia, the presence of normal intestinal flora was required (1-3).

Hemorrhage, especially gastrointestinal, developing during the operations could lead to major alterations in BUN levels of the animals. But use of the same procedures for both groups, control and study, and attention to good hemostasis during the operations eliminated such a complication. This is verified by the parallel course of BUN levels in the two groups.

How the reabsorbed labeled-nitrogen was metabolized or into which molecules it was incorporated could not be determined in this study.

Long-term follow-up was not possible because of the short half-life of the radiopharmaceutical and the short life expectancy of the nephrectomized animals.

In conclusion, the results of this study suggest that when the bacterial flora of the intestinal system is changed to include bacteria involved in the nitrogen cycle in uremic rabbits, both intraintestinal and systemic nitrogen metabolism could be altered in favor of positive nitrogen balance. However, more detailed studies should be performed to determine how the metabolism of urea nitrogen occurs and what kind of organic compounds are formed by these bacteria.

\section{Acknowledgments}

We thank the Carmosan-Milupa Company very much for its financial support in this study.

\section{REFERENCES}

1) Wrong O. 1978. Nitrogen metabolism in the gut. Am J Clin Nutr 31: 1587-1593.

2) Wilson DR, Ing TS, Metcalfe-Gibson A, Wrong OM. 1968. In vivo dialysis of faeces as a method of stool analysis. III. The effect of intestinal antibiotics. Clin Sci 34: 211-221.

3) Wilson DR, Ing TS, Metcalfe-Gibson A, Wrong OM. 1968. The chemical composition of faeces in uremia, as revealed by in vivo faecal dialysis. Clin Sci 35: 197209.

4) Mitch WE, Walser M. 1977. Effects of oral neomycin and kanamycin in chronic uremic patients. II. Nitrogen balance. Kidney Int 11: 123-127.

5) Jones EA, Smallwood RA, Craigie A, Rosenoer VM. 1969. The enterohepatic circulation of urea nitrogen. Clin Sci 37: 825-836. 
6) Walser M, Coulter AW, Dighe S. 1973. The effect of ketoanalogues of essential amino acids in severe chronic uremia. J Clin Invest 52: 678-690.

7) Ingraham JL, Wheelis ML, Painter PR. 1987. Microorganisms as geochemical agents. In: General Microbiology, 5th ed, (Stanier RY, Ingraham JL, Wheelis ML, Painter PR, eds), p 545-558. Macmillan, Houndmills.

8) Ingraham JL, Wheelis ML, Painter PR. 1987. The chemoautotrophic and methophilic eubacteria. In: General Microbiology, 5th ed, (Stanier RY, Ingraham JL, Wheelis ML, Painter PR, eds), p 383-401. Macmillan, Houndmills.

9) Jesseph JE, Csicsko JF. 1977. Miscellaneous techniques for operations on the stomach and duodenum. In: Surgery of the Stomach and Duodenum, 3rd ed, (Nyhus LM, Wastell C, eds), p 715-746. Little, Brown and Company, Boston.

10) Trolldenier G. 1995. Nitrifiers by MPN method. In: Methods in Soil Biology (Schinner F, Ohlinger R, Kandeler E, Margesin E, eds), p 32. Springer Verlag, Berlin.

11) MPN method. 1985. Standard Methods for the Examination of Water and Wastewater, 19th ed (Eaton
$\mathrm{AD}$, Clesceri LS, Greenberg AE, eds), p 9.48-9.50. American Public Health Association, Washington DC.

12) Vincent JM. 1970. A Manual for the Practical Study of Root-Nodule Bacteria, p 163. Blackwell, Oxford.

13) Roberfroid MB. 2000. Prebiotics and probiotics: are they functional foods? Am J Clin Nutr 71(6 Suppl): $1682 \mathrm{~S}-1687 \mathrm{~S}$.

14) Arambel MJ, Kent BA. 1990. Effect of yeast culture on nutrient digestibility and milk yield response in early to midlactation dairy cows. J Dairy Sci 73: 1560 1563.

15) Teller E, Godeau JM. 1986. Some attempts to improve the nutritive value of urea for dairy cows. II. Its administration in a slightly soluble form: isobutylidene diurea (IBDU). Arch Tierernahr 36: 419-428 (abstract).

16) Voigt J, Piatkowski B, Krawielitzki R, Bergner H, Gorsch R. 1981. Isobutylidene diurea as an NPN source for ruminants. 1. Rumen fermentation, digestibility of the nutrients and microbial protein synthesis in dairy cows. Arch Tierernahr 31: 45-56 (abstract).

17) Mallol J, Bonino C. 1997. Comparison of radiochemical purity control methods for Tc-99m radiopharmaceuticals. Nucl Med Commun 18(5): 419-422. 